\title{
Malignant thrombosis of the superior vena cava caused by non-small-cell lung cancer treated with radiation and erlotinib: a case with complete and prolonged response over 3 years
}

\author{
This article was published in the following Dove Press journal: \\ OncoTargets and Therapy \\ 28 June 2013 \\ Number of times this article has been viewed
}

\author{
Jianyang Wang' \\ Jun Liang' \\ Wenqing Wang' \\ Han Ouyang ${ }^{2}$ \\ Luhua Wang' \\ 'Department of Radiation Oncology, \\ Cancer Hospital and Institute, \\ Chinese Academy of Medical Sciences \\ and Peking Union Medical College, \\ Beijing, ${ }^{2}$ Department of Diagnostic \\ Radiology, Cancer Hospital and \\ Institute, Chinese Academy of Medical \\ Sciences and Peking Union Medical \\ College, Beijing, People's Republic \\ of China
}

\begin{abstract}
Most cases of superior vena cava (SVC) syndrome resulting from neoplasm, especially from lung cancer, remain a serious challenge to treat. Here, for the first time as far as we are aware, we report the case of a non-small-cell lung cancer patient with a massive SVC malignant thrombosis who was treated with thoracic irradiation and erlotinib. The treatment regimen consisted of erlotinib $150 \mathrm{mg} /$ day and a total dose of $66 \mathrm{~Gy} / 33$ fractions delivered to the tumor, malignant thrombosis, and metastasis mediastinal lymph nodes. The malignant thrombosis responded dramatically and the combined regimen was well tolerated. After discharge, the erlotinib was prescribed as maintenance therapy. The patient was followed closely for the next 3 years. During this time, positron emission tomography/computed tomography scans and serum tumor marker screens were undertaken. By 6 months, the primary tumor showed complete response and by 9 months, the SVC thrombosis had disappeared. No sign of relapse has been found to date.
\end{abstract}

Keywords: superior vena cava syndrome, radiotherapy, thoracic irradiation, neoplasm

\section{Introduction}

The majority of cases of superior vena cava (SVC) syndrome result from neoplasm, particularly lung cancer. ${ }^{1}$ Here, for the first time as far as we are aware, we report the case of a non-small-cell lung cancer (NSCLC) patient with massive SVC malignant thrombosis who was treated with thoracic irradiation and erlotinib, subsequently achieving complete remission of the cancer and long-term disease-free survival over 3 years.

\section{Case report}

A 61-year-old man presented to the hospital with a 3-month history of progressive edema of the head, neck, arms, and upper chest, followed by shortness of breath and distention of the jugular and chest veins. The medical history of the patient revealed 30 years of tobacco use. The whole-body positron emission tomography/computed tomography $(\mathrm{PET} / \mathrm{CT})$ scan revealed a mass $(1.5 \times 1.0 \mathrm{~cm})$ in the upper lobe of the right lung, with a maximal standard uptake value $\left(\mathrm{SUV}_{\max }\right)$ of 4.2 ; enlarged lymph nodes in levels 1, 2R, and 4R; and a huge $7.4 \mathrm{~cm}$ long mass with a $\mathrm{SUV}_{\max }$ of 8.9 (Figure 1A) inside the SVC, which was confirmed by magnetic resonance imaging (Figure 1B). Core needle biopsy samples of the enlarged lymph nodes yielded NSCLC (possibly adenocarcinoma) with epidermal growth factor receptor (EGFR) protein expression. Owing to inadequate tumor sample volume, the EGFR gene was not tested
Correspondence: Luhua Wang Department of Radiation Oncology, Cancer Hospital and Institute, Panjiayuan Nanli \#17, Chaoyang District, Beijing 10002I, People's

Republic of China

Tel +861087788799

Fax +861067706153

Emailwlhwq@yahoo.com 
A

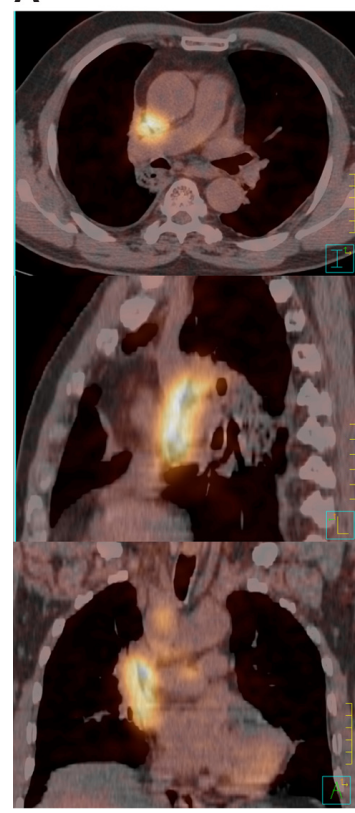

B

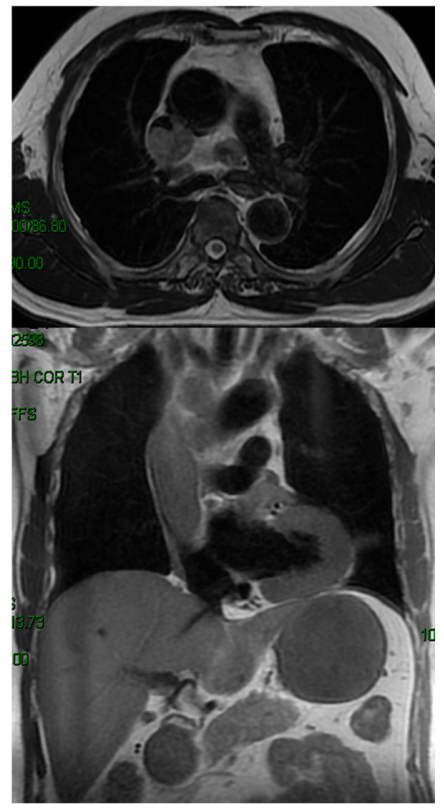

Figure I Malignant thrombosis of the superior vena cava before treatment: (A) whole-body positron emission tomography/computed tomography scan; (B) magnetic resonance image. for somatic mutation. No evidence of distant metastasis was found and the disease was diagnosed as primary adenocarcinoma of the lung (cT1N2M0), with malignant thrombosis of the SVC.

After consulting with the oncologists, the patient was treated with thoracic intensity-modulated radiation therapy and erlotinib at a dosage of $150 \mathrm{mg} / \mathrm{day}$, in order to avoid chemotherapy which may result in nausea and vomiting, could cause the drop of thrombosis. A loop diuretic (hydrochlorothiazide $50 \mathrm{mg}$ ) was also used to relieve the SVC syndrome for the first week. Thoracic intensity-modulated radiation therapy was delivered to the planning target volume at a total dose of 66 Gy at 2 Gy per fraction (five times per week). The planning target volume was created by a $5 \mathrm{~mm}$ isotropic expansion of the clinical target volume, which encompassed the gross tumor volume and the subcarinal nodes, ipsilateral mediastinum, and ipsilateral hilum. The gross tumor volume was contoured according to the PET/CT images, which included a primary lesion in the right upper lung, metastatic mediastinal lymph nodes, and malignant thrombosis of the

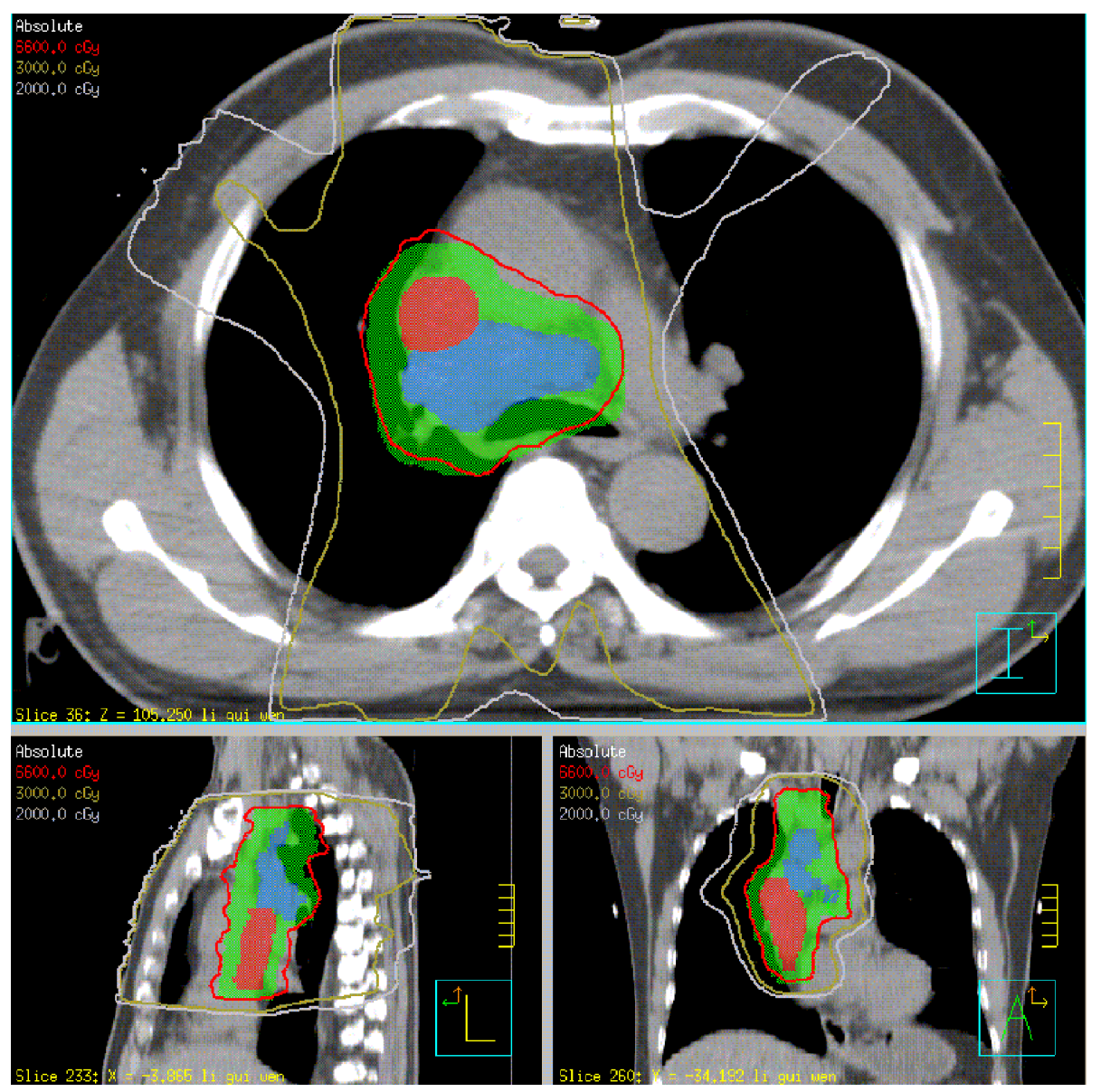

Figure 2 Dose distribution in the primary intensity-modulated radiation therapy. The red, olive, and grey lines represent dose distributions of 66,30 , and 20 Gy, respectively. The red, blue, and green areas represent malignant thrombosis in the superior vena cava, metastatic lymph nodes, and the planning target volume, respectively. Notes: "I" indicates Inferior, "L" Left and "A" Anterior, which represents the directions of view of the patient. 
SVC (Figure 2). During weekly physical examinations of the patient, the distention of the jugular and chest veins was found to have resolved completely following radiotherapy delivered at 22 Gy, while significant tumor remission was observed after radiation treatment at 40 Gy (Figure 3).

On discharge, the patient was prescribed erlotinib (150 mg/day) as maintenance therapy and monitored closely for the following 45 months with PET/CT scans and serum tumor marker (STM) screens every 3 months. At 6 months after treatment, the primary tumor was found to have completely responded and at 9 months post-treatment, the SVC thrombosis had disappeared. In addition, no signs of pulmonary interstitial abnormality were observed on PET/CT. All the STMs were controlled and the lymph nodes that had been enlarged before treatment were found to have shrunk significantly without abnormal SUV elevation by the last follow-up (Figure 4).

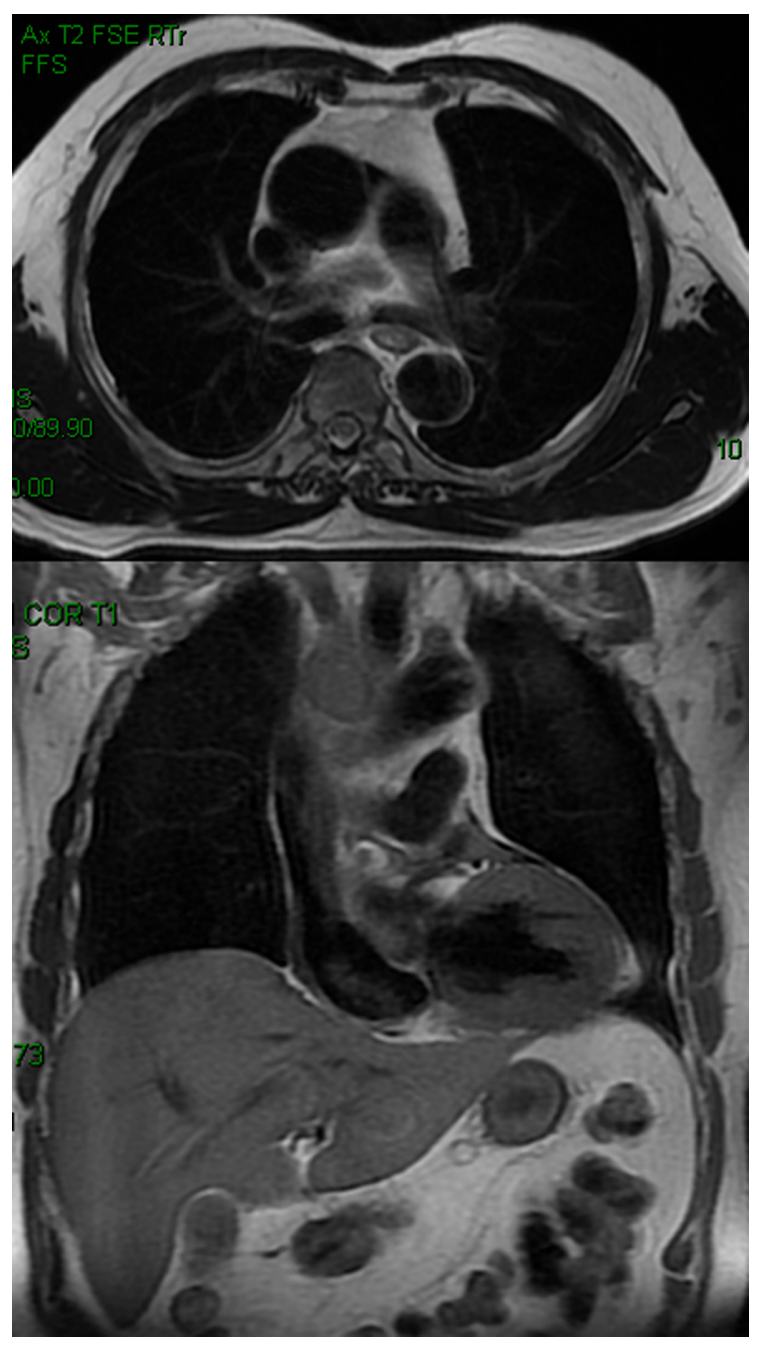

Figure $3 \mathrm{Tl}$-weighted images showing residual malignant thrombosis of the superior vena cava at $40 \mathrm{~Gy}$.

\section{Discussion}

For patients with SVC syndrome resulting from intravascular thrombus by neoplasm, the prognosis is quite poor, and the condition carries a median life expectancy of 6 months and a 2-year survival rate of 5\%, although estimates vary widely according to the underlying malignant conditions. ${ }^{2-6}$ However, the patient in this study continues to enjoy a disease-free survival time beyond 3 years. To our knowledge, this is the first report of conventional radiotherapy combined with erlotinib inducing complete remission and long-term disease-free survival time in NSCLC with malignant thrombosis of the SVC.

Erlotinib has been used to treat NSCLC patients with SVC syndrome in the past, ${ }^{7,8}$ and the tumors in these cases completely responded to the erlotinib. In one of these cases, ${ }^{7}$ erlotinib was used concurrently with stereotactic body radiation therapy. However, regardless of the therapeutic effect, the patient developed radiation pneumonitis 3 months after treatment, with suspected interstitial lung disease. The most serious toxicity of tyrosine kinase inhibitors is interstitial lung disease. A previous study has implied that prior tissue injury from radiation therapy could lead to cells having altered responses to drugs administered subsequently. ${ }^{9}$ Thus, it is possible for erlotinib to induce an altered response in normal tissue, such as in the lung. However, our patient showed good tolerance of the radiotherapy and erlotinib without symptomatic or radiographic radiation pneumonitis. It could be supposed that the difference in fractionated dose between conventionally fractionated radiotherapy and stereotactic body radiation therapy has a unique impact on radiation pneumonitis. In relation to acute radiation pneumonitis, continuous hyperfractionated accelerated radiotherapy is better tolerated than conventionally fractionated radiotherapy. ${ }^{10}$ Thus, conventionally fractionated individual doses of 2 Gy might have fewer side effects on the pulmonary system. The total dose and mean lung dose should be also considered.

It is unfortunate that we did not obtain information about the presence or lack of somatic mutation in the EGFR gene of the tumor, just as in a previously reported case, ${ }^{8}$ as this has been associated with a higher responsiveness to erlotinib. ${ }^{11}$ We were limited by the biopsy sample volume and by the need to treat the SVC obstruction, as EGFR gene sequencing usually takes 1 to 2 weeks. Nevertheless, we recommend testing for the EGFR gene mutation to guide the tyrosine kinase inhibitor treatment, as less than $30 \%$ of unselected patients have been found to carry the mutation. ${ }^{12,13}$

Owing to the rarity of SVC syndrome caused by malignant thrombosis, such cases represent a serious challenge to both internists and oncologists. There are no formal professional 


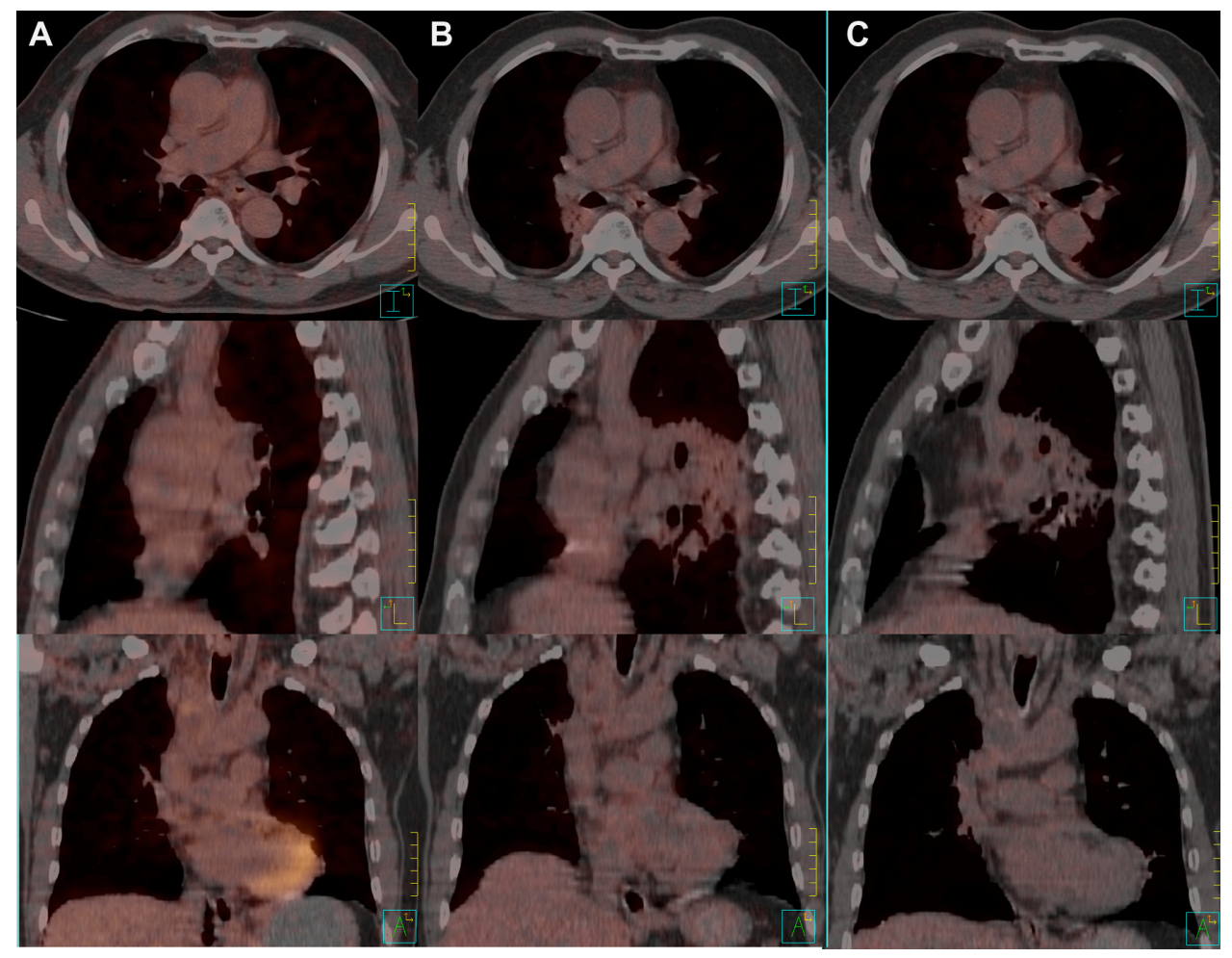

Figure 4 Positron emission tomography/computed tomography images showing the superior vena cava during follow-up at I month (A), 3 months (B), and 45 months (C).

guidelines addressing the management of SVC obstruction. Most data regarding management of SVC syndrome are from case series; randomized trials are scarce. Besides best supportive care and treatment to relieve symptoms, such as diuretics and corticosteroids, certain emergent treatments can be considered. ${ }^{14-16}$ Percutaneous placement of an intravascular stent to bypass the obstruction of the SVC is a possible intervention. Because the stent can be placed before a tissue diagnosis is available, it is a useful procedure for patients with severe symptoms, such as respiratory distress that require urgent intervention. Complications of stent placement have been reported in $3 \%-5 \%$ of patients with SVC syndrome, including infection, pulmonary embolus, stent migration, hematoma at the insertion site, bleeding, and, very rarely, perforation. ${ }^{6,17,18}$ Another, less common, treatment is surgical bypass grafting when no original malignancies are found or when they are not sensitive to chemotherapy or radiotherapy. Bypass grafting that involves a subcutaneous jugular-femoral graft, for example, ${ }^{19}$ can be performed with relatively few complications. A more common approach is sternotomy or thoracotomy with extensive resection and reconstruction of the SVC. Case series indicate an operative mortality of approximately $5 \% .^{16,20,21}$

Further treatment of the original malignancy should not be compromised after symptom remission and is usually guided by the histology of the tumor. For example, in patients with lymphoma, small-cell lung cancer, or germ-cell tumors, the clinical response to systemic chemotherapy alone is typically rapid. For patients with NSCLC, chemotherapy (Stage IV disease) or chemotherapy combined with radiotherapy (Stage III disease) should be considered. Stent placement should also be strongly considered for patients with mesothelioma, which tends not to respond well to chemotherapy or radiation. In addition, surgery is often appropriate when SVC syndrome has been caused by a thymoma, which is relatively resistant to chemotherapy and radiation compared with lymphomas.

The other main clinical reason for an SVC is when patients have been at risk of a thrombotic complication because of cancer. Patients with cancer who develop thrombosis have a poor prognosis, and their risk of dying after an acute thrombotic event is four- to eightfold higher than patients without cancer. ${ }^{22}$ However, the benefit of either short- or long-term anticoagulation therapy for this syndrome is unclear.

\section{Conclusion}

Based on the general recommendation of the American College of Chest Physicians ${ }^{23}$ and the National Comprehensive Cancer Network $^{24}$ for radiotherapy, we suggest that radiotherapy combined with erlotinib be considered for selected Stage III NSCLC patients with malignant thrombosis of the SVC, rather than chemotherapy, which may cause nausea and 
vomiting and carries the risk of cardiovascular embolism. However, the safety and efficiency of this combined regimen should be further explored in clinical trials.

\section{Disclosure}

The authors declare no relationships with industry and organizations or potential conflicts of interest between the authors and other persons in relation to this work. All authors read and approved the final manuscript for publication.

\section{References}

1. Wilson LD, Detterbeck FC, Yahalom J. Clinical practice. Superior vena cava syndrome with malignant causes. $N$ Engl J Med. 2007;356(18): $1862-1869$.

2. Schraufnagel DE, Hill R, Leech JA, Pare JA. Superior vena caval obstruction. Is it a medical emergency? Am J Med. 1981;70(6):1169-1174.

3. Yellin A, Rosen A, Reichert N, Lieberman Y. Superior vena cava syndrome. The myth - the facts. Am Rev Respir Dis. 1990;141(5 Pt 1): $1114-1118$

4. Tanigawa N, Sawada S, Mishima K, et al. Clinical outcome of stenting in superior vena cava syndrome associated with malignant tumors. Comparison with conventional treatment. Acta Radiol. 1998;39(6): 669-674.

5. Marcy PY, Magne N, Bentolila F, Drouillard J, Bruneton JN, Descamps B. Superior Vena cava obstruction: is stenting necessary? Support Care Cancer. 2001;9(2):103-107.

6. Greillier L, Barlési F, Doddoli C, et al. Vascular stenting for palliation of superior vena cava obstruction in non-small-cell lung cancer patients: a future 'standard' procedure? Respiration. 2004;71(2):178-183.

7. Hsieh CH, Chang HT, Lin SC, et al. Toxic risk of stereotactic body radiotherapy and concurrent helical tomotherapy followed by erlotinib for non-small-cell lung cancer treatment - case report. BMC Cancer. 2010;10:696-670.

8. Salmi R, Gaudenzi P, Di Todaro F, Morandi P, Nielsen I, Manfredini R. Massive thrombosis of brachiocephalic veins and superior vena cava syndrome in a patient with non-small cell lung cancer treated with the epidermal growth factor receptor inhibitor erlotinib. Clin Drug Investig. 2007;27(7):499-503.

9. Kitani H, Kosaka T, Fujihara T, Lindquist K, Elkind MM. The "recall effect" in radiotherapy: is subeffective, reparable damage involved? Int J Radiat Oncol Biol Phys. 1990;18(3):689-695.

10. Jenkins P, D'Amico K, Benstead K, Elyan S. Radiation pneumonitis following treatment of non-small-cell lung cancer with continuous hyperfractionated accelerated radiotherapy (CHART). Int $J$ Radiat Oncol Biol Phys. 2003;56(2):360-366.
11. Tsao MS, Sakurada A, Cutz JC, et al. Erlotinib in lung cancer-molecular and clinical predictors of outcome. $N$ Engl J Med. 2005;353(2): 133-144.

12. Shepherd FA, Rodrigues Pereira J, Ciuleanu T, et al; National Cancer Institute of Canada Clinical Trials Group. Erlotinib in previously treated non-small-cell lung cancer. N Engl J Med. 2005;353(2):123-132.

13. Dong QG, Han BH, Huang JS, et al. Analysis of EGFR mutations in 176 cases of non-small cell lung cancer. Zhonghua Zhong Liu Za Zhi. 2006;28(9):686-690. Chinese.

14. Yim CD, Sane SS, Bjarnason H. Superior vena cava stenting. Radiol Clin North Am. 2000;38(2):409-424.

15. Thony F, Moro D, Witmeyer P, et al. Endovascular treatment of superior vena cava obstruction in patients with malignancies. Eur Radiol. 1999;9(5):965-971.

16. Shen KR, Meyers BF, Larner JM, Jones DR; American College of Chest Physicians. Special Treatment Issues in Lung Cancer: ACCP EvidenceBased Clinical Practice Guidelines, 2nd ed. Chest. 2007;132(Suppl 3): 290S-305S.

17. Nicholson AA, Ettles DF, Arnold A, Greenstone M, Dyet JF. Treatment of malignant superior vena cava obstruction: metal stents or radiation therapy. J Vasc Interv Radiol. 1997;8(5):781-788.

18. Urruticoechea A, Mesía R, Domínguez J, et al. Treatment of malignant superior vena cava syndrome by endovascular stent insertion. Experience on 52 patients with lung cancer. Lung Cancer. 2004;43(2):209-214.

19. Dhaliwal RS, Das D, Luthra S, Singh J, Mehta S, Singh H. Management of superior vena cava syndrome by internal jugular to femoral vein bypass. Ann Thorac Surg. 2006;82(1):310-312.

20. Chen KN, Xu SF, Gu ZD, et al. Surgical treatment of complex malignant anterior mediastinal tumors invading the superior vena cava. World $J$ Surg. 2006;30(2):162-170.

21. Inoue $\mathrm{M}$, Minami $\mathrm{M}$, Shiono $\mathrm{H}$, et al. Efficient clinical application of percutaneous cardiopulmonary support for perioperative management of a huge anterior mediastinal tumor. J Thorac Cardiovasc Surg. 2006;131(3):755-756

22. Levitan N, Dowlati A, Remick Sc, et al. Rates of initial and recurrent thromboembolic disease among patients with malignancy versus those without malignancy. Risk analysis using Medicare claims data. Medicine (Baltimore). 1999; 78(5):285-291.

23. Kvale Pa, Simoff M, Prakash Ub. Lung Cancer. Palliative Care. Chest. 2003;123(Suppl 1):284S-311S.

24. National Comprehensive Cancer Network (NCCN). NCCN Clinical Practice Guidelines in Oncology: Non-Small Cell Lung Cancer. V.I.2007. Fort Washington, PA: NCCN; 2007. Available from: http:// www.nccn.org/professionals/physician_gls/pdf/nscl.pdf. Accessed April 9, 2007.
OncoTargets and Therapy

\section{Publish your work in this journal}

OncoTargets and Therapy is an international, peer-reviewed, open access journal focusing on the pathological basis of all cancers, potential targets for therapy and treatment protocols employed to improve the management of cancer patients. The journal also focuses on the impact of management programs and new therapeutic agents and protocols on

\section{Dovepress}

patient perspectives such as quality of life, adherence and satisfaction. The manuscript management system is completely online and includes a very quick and fair peer-review system, which is all easy to use. Visit http://www.dovepress.com/testimonials.php to read real quotes from published authors. 